\title{
Analysis of fatty acid composition in edible oils by gas chromatography
}

\author{
Ivana Đuričić*, Milica Jović, \\ Vanja Todorović, Slađana Šobajić \\ Farmaceutski fakultet Univerziteta u \\ Beogradu, Katedra za bromatologiju, \\ Vojvode Stepe 450, 11221 Beograd, Serbia \\ *Corresponding author: \\ Ivana Đuričić \\ Institute of bromatology, Faculty of \\ pharmacy, University of Belgrade, Vojvode \\ Stepe 450, 11000 Belgrade, Srbia \\ Phone: +381 113951393 \\ E-mail address: ivanadj@pharmacy.bg.ac.rs
}

\begin{abstract}
Edible oils are recognised as essential nutrients in the human modern diet as they are one of the concentrated sources of energy that provide essential fatty acids, liposoluble vitamins ( $A, D, E$ and $K$ ) and provitamins (carotene). This study was aimed to characterize fatty acid profile in different edible oils available on Serbian market, consider the benefits of certain oils use in the diet and their thermal stability according to a particular composition. Nineteen samples of edible oils were esterified with $\mathrm{HCl}$ in methanol. Fatty acid methyl esters were then examined by gas chromatography on apparatus Agilent Technologies 7890A with a flame ionization detector. Results are expressed as a percentage of an individual fatty acid normalised to the total amount of all fatty acids measured in the sample. Coconut and palm fruit oils were certainly distinguished by saturated fatty acid content $(95.4 \%$ and $49.2 \%$, respectively). In terms of linoleic acid content, the following samples were grouped: evening primrose oil, grape oil, poppyseed oil, sunflower oil, and hemp oil. The specificity of mustard oil in the presence of erucic acid was also noted. The highest proportion of a-linolenic acid (51.2\%) was determined for flaxseed oil followed by hemp seed oil. Due to the high content of saturated fatty acids, coconut and palm oil could be considered the most stable ones among all tested samples. Oils containing essential linoleic and a-linolenic fatty acids should be used as unrefined vegetable oils in order to preserve active ingredients with beneficial health effects.
\end{abstract}

Keywords: edible oils, saturated fatty acids, unsaturated fatty acids, essential fatty acids, gas chromatography.

\section{UVOD}

Lipidi su makronutrijenti čija je uloga u organizmu mnogostruka. Neophodni su za izgradnju ćelijskih membrana, sintezu brojnih hormona, izvori su liposolubilnih vitamina, provitamina i predstavljaju najznačajniji izvor energije, stoga ih je bitno unositi hranom u dovoljnim količinama. Prema principima racionalne ishrane $25-30 \%$ ukupnih dnevnih energetskih potreba treba da potiče od lipida unetih hranom [1]. Jestivim uljima i mastima čovek obično zadovoljava polovinu svojih dnevnih potreba za lipidima, a ostatak unosi u obliku skrivenih masti unošenjem namirnica biljnog $i$ životinjskog porekla (meso, jaja, mleko, pekarski proizvodi, badem, lešnik, orah) [2].

Sa aspekta hemije, lipidi su heterogena grupa jedinjenja različite hemijske strukture, a zajednička osobina im je da su nerastvorni u vodi, a rastvorni u organskim rastvaračima. Ulja su smeše lipida tečne konzistencije na sobnoj temperaturi, dok su masti smeše lipida čvrste na sobnoj temperaturi. Biljna ulja se dobijaju presovanjem ili ekstrakcijom pripremljenih semenki, plodova, koštica raznog voća, klica žitarica i drugog biljnog materijala.

Jestiva biljna ulja mogu se proizvoditi i stavljati u promet pod sledećim nazivom [3]:

1. hladno presovano jestivo biljno ulje, sa naznakom sirovine

2. devičansko jestivo biljno ulje, sa naznakom sirovine

3. jestivo nerafinisano biljno ulje, bez naznake sirovine

4. jestivo rafinisano biljno ulje, sa naznakom sirovine

5. mešano jestivo rafinisano biljno ulje, bez naznake sirovine

6. mešano jestivo biljno ulje, bez naznake sirovine

Hladno presovano jestivo biljno ulje proizvodi se mehaničkim postupkom, presovanjem bez zagrevanja. $\mathrm{U}$ toku proizvodnje moraju se sačuvati prirodni sastojci ulja u nepromenjenom obliku. Ova biljna ulja se mogu prečišćavati isključivo taloženjem, filtracijom, centrifugiranjem i pranjem sa vodom. Devičansko jestivo biljno ulje proizvodi se presovanjem. Pri izdvajanju ulja dozvoljeno je zagrevanje materijala za presovanje. Jestivo nerafinisano biljno ulje dobija se mešanjem hladno 
presovanih jestivih biljnih ulja i/ili devičanskih jestivih biljnih ulja. Jestivo rafinisano biljno ulje proizvodi se čišćenjem (odstranjivanje nečistoća), ljuštenjem i usitnjavanjem mehaničkim putem i presovanjem i/ili ekstrakcijom sa rastvaračem i/ili rafinacijom. Mešano jestivo rafinisano biljno ulje dobija se mešanjem jestivih rafinisanih biljnih ulja. Mešano jestivo biljno ulje dobija se mešanjem hladno presovanih jestivih biljnih ulja i/ili devičanskih jestivih biljnih ulja i/ili rafinisanih jestivih biljnih ulja.

U pogledu masnokiselinskog sastava, masti imaju veći udeo zasićenih masnih kiselina i zbog toga su termički stabilnije, dok ulja imaju generalno veći udeo nezasićenih masnih kiselina te su podložnija termičkoj degradaciji [4].

Biljna ulja su jedna od značajnih komponenti savremene ishrane čoveka. Izvor su esencijalnih masnih kiselina linolne (LA, 18:2) i a-linolenske kiseline (ALA, 18:3). Ove dve masne kiseline se u većoj količini nalaze u namirnicama kao što su ulje soje, lana, seme bundeve, suncokreta, orasi. S obzirom da su jako važne za brojne metaboličke procese u organizmu, postoje dokazi da nedostatak esencijalnih masnih kiselina može biti uzročnik mnogih patoloških stanja: dermatitisa, usporenog rasta, renalne hipertenzije, poremećaja u aktivnosti mitohondrija, radu srca i cirkulaciji, razvoja dijabetesa tipa 2, poremećaja u razvoju mozga, artritisa, depresije, smanjene otpornosti organizma [5].

Cilj ovog rada bio je određivanje kvalitativnog i kvantitativnog sastava masnih kiselina u jestivim biljnim uljima dostupnim na tržištu Srbije, razmatranje koristi od upotrebe pojedinih ulja u ishrani, kao i njihove termičke stabilnosti u odnosu na sastav masnih kiselina.

\section{MATERIJAL I METODE}

Devetnaest vrsta nerafinisanih jestivih biljnih ulja dostupnih na tržištu Srbije analizirano je u ovoj studiji. Istraživanje je obuhvatilo sledeća ulja: semena lana, semena slačice, semena uljane repice, semena konoplje, semena crnog kima, semena kikirikija, semena badema, koštice kajsije, semena susama, semena grožđa, pšeničnih klica, semena bundeve, semena maka, ploda palme, ploda kokosa, semena noćuraka, ploda masline, ploda soje, semena suncokreta.

\section{Određivanje sastava i sadržaja masnih kiselina}

Sastav masnih kiselina u uzorcima ulja određen je metodom gasne hromatografije. Izvršena je derivatizacija masnih kiselina $u$ isparljive metil-estre transesterifikacijom rastvorom $\mathrm{HCl}$ u metanolu, kako je opisano $\mathrm{u}$ metodi autora Ichihara i Fukubayashi [6]. Metil estri masnih kiselina su ispitivani metodom gasne hromatografije na aparatu Agilent Technologies 7890A sa plameno jonizacionim detektorom. Korišćena je kapilarna kolona CP-Sil $88(100 \mathrm{~m} \times 0,25 \mathrm{~mm} \times 0,2 \mu \mathrm{m})$, helijum je bio noseći gas sa protokom od $1 \mathrm{ml} / \mathrm{min}$. Uzorci su injektovani na temperaturi kolone od $80^{\circ} \mathrm{C}$, temperatura injektora je bila $250^{\circ} \mathrm{C}$, a detektora $270^{\circ} \mathrm{C}$. Temperatura kolone se povećavala sa $80^{\circ} \mathrm{C}, 4^{\circ} \mathrm{C}$ min- 1 do $220^{\circ} \mathrm{C}$, $5 \mathrm{~min}$, a zatim $4^{\circ} \mathrm{C}$ min-1 do $240{ }^{\circ} \mathrm{C}, 10 \mathrm{~min}$. Masne kiseline su identifikovane na osnovu retencionih vremena standardne smeše masnih kiselina (Supelco FAME Mix, Bellefonte, PA). Efikasnost kolone je prikazana kroz broj teoretskih platoa 4 standardne masne kiseline (palmitinske, stearinske, oleinske i lonolne) u rasponu od 362870-649372, dok je ponovljivost odgovora određena kao procenat relativne standardne devijacije (RSD \%) uzastopnih merenja istog referentnog rastvora u rasponu od 0,3-4,6\%.

Sadržaj masnih kiselina je određen računski, kao procenat pojedinačnih masnih kiselina u odnosu na ukupne masne kiseline za dati uzorak. Sva ulja su uzorkovana u triplikatu. Shodno veoma niskoj varijaciji podataka (SD $<0,1)$, rezultati su prikazani kao srednja vrednost.

Rezultati istraživanja su sistematizovani i prikazani tabelarno i grafički upotrebom Word i GraphPad 6 Prism programa.

\section{REZULTATI I DISKUSIJA}

Rezultati sadržaja zasićenih i nezasićenih masnih kiselina u analiziranim uzorcima jestivih biljnih ulja prikazani su Tabeli 1.

\section{Ulja sa visokim sadržajem zasićenih masnih kiselina (ZMK)}

Ulja ploda palme i kokosa okarakterisana su visokim sadržajem ZMK. Ukupan sadržaj ZMK palminog ulja je $49,2 \%$, što odgovara rezultatima dobijenim u drugim studijama gde su te vrednosti oko $50 \%[7,8]$. Od pojedinačnih masnih kiselina, zabeležena je najveća količina palmitinske kiseline $(45,7 \%)$, i u značajno manjem procentu stearinska kiselina (3,7 \%). U kokosovom ulju profil zasićenih masnih kiselina je znatno raznovrsniji, te je najzastupljenija bila laurinska kiselina sa 47,5 \%, koju su pratile mirsinska, kaprilna, palmitinska, kaprinska i stearinska kiselina (Grafikon 1). Odnos zasićenih i nezasićenih masti kokosovog ulja je $\sim 19$, dok u slučaju palminog ulja iznosi $~ 1$.

Zbog visokog udela ZMK i visokih vrednosti tačke dimljenja, palmino i kokosovo ulje su pogodni za termičku obradu [8]. Zasićene masne kiseline nemaju dvostruke veze, stoga ne podležu termičkoj oksidaciji i ne dovode do nastanka reaktivnih kiseoničnih vrsta (ROS) koje nepovoljno utiču na brojne fiziološke procese $u$ organizmu. Takođe, kokosovo ulje se izdvaja i sa metaboličkog aspekta. Naime, ono sadrži najveći procenat masnih kiselina srednje dužine lanca, koje u svom sastavu imaju 8 do $12 \mathrm{C}$ atoma. Ove masne kiseline se apsorbuju i transportuju portalnom cirkulacijom direktno u jetru, gde se koriste za dobijanje energije. 
Tabela 1: Sastav masnih kiselina (izražen u \%) u ispitivanim biljnim uljima.

\begin{tabular}{|c|c|c|c|c|c|c|c|c|}
\hline \multirow[t]{2}{*}{ Ulje } & \multicolumn{2}{|c|}{$Z M K$} & \multirow[t]{2}{*}{$\Sigma Z M K$} & \multirow{2}{*}{$\begin{array}{c}\text { ММК } \\
\text { C 18:1 }\end{array}$} & \multicolumn{2}{|c|}{ PMK } & \multirow[t]{2}{*}{$\Sigma M M K$} & \multirow[t]{2}{*}{$\Sigma P M K$} \\
\hline & C 16:0 & C 18:0 & & & C 18:2 & C $18: 3$ & & \\
\hline Seme lana & 6,7 & 5,3 & 12 & 20,6 & 15,4 & 51,2 & 20,6 & 66,6 \\
\hline Seme slačice & 4,4 & 1,2 & 5,6 & 21,9 & 10,5 & 6,2 & 63,5 & 16,7 \\
\hline Seme uljane repice & 5,9 & 1,5 & 7,4 & 61,6 & 20,9 & 8,1 & 61,6 & 29 \\
\hline Seme konoplje & 8,5 & 3,5 & 12 & 14,8 & 55,1 & 16,2 & 14,8 & 71,3 \\
\hline Seme crnog kima & 10,7 & 2,6 & 13,3 & 33 & 49,7 & 1,5 & 33 & 51,2 \\
\hline Semena kikirikija & 14,5 & 4,5 & 19 & 44,4 & 29,6 & 0,7 & 44,4 & 30,3 \\
\hline Seme badema & 7,8 & 1,3 & 9,1 & 62,6 & 27,9 & & 62,6 & 27,9 \\
\hline Koštice kajsije & 6,7 & 1,4 & 8,1 & 61,7 & 29,4 & & 61,7 & 29,4 \\
\hline Seme susama & 11,3 & 5,2 & 16,5 & 41,5 & 42 & & 41,5 & 42 \\
\hline Seme grožđa & 8,5 & 4,8 & 14,3 & 19,8 & 66,2 & & 19,8 & 66,2 \\
\hline Pšenične klice & 18,2 & 1,6 & 19,8 & 20.3 & 54,3 & 5,6 & 20,3 & 59,9 \\
\hline Seme bundeve & 15 & 4,6 & 19,6 & 35,3 & 44,6 & 0,5 & 35,3 & 45,1 \\
\hline Seme maka & 12,1 & 2 & 14,1 & 21,2 & 63,2 & 1,6 & 21,2 & 64,8 \\
\hline Plod palme & 45,5 & 3,7 & 49,2 & 39,5 & 10,2 & & 39,5 & 10,2 \\
\hline Plod kokosa & 8,5 & 2,7 & 95,4 & 4,1 & 0,5 & & 4,1 & 0,5 \\
\hline Seme noćurka & 7,1 & 2,3 & 9,4 & 7 & 75,1 & $8,6^{*}$ & 7 & 83,7 \\
\hline Plod masline & 10,1 & 3,2 & 13,3 & 78,5 & 8,2 & & 78,5 & 8,2 \\
\hline Plod soje & 10,6 & 5,9 & 16,5 & 26,8 & 50,9 & 5,8 & 26,8 & 56,7 \\
\hline Seme suncokreta & 6 & 4,3 & 10,3 & 28,4 & 59,7 & & 28,4 & 59,7 \\
\hline
\end{tabular}

ZMK - zasićene masne kiseline; MMK - mononezasićene masne kiseline; PMK - polinezasićene masne kiseline; C 16:0 - Palmitinska; $\mathbf{C}$ 18:0 - Stearinska; C 18:1 - Oleinska; C 18:2 - Linolna; C 18:3 - a-Linolenska; ${ }^{*}{ }^{-}$-Linolenska

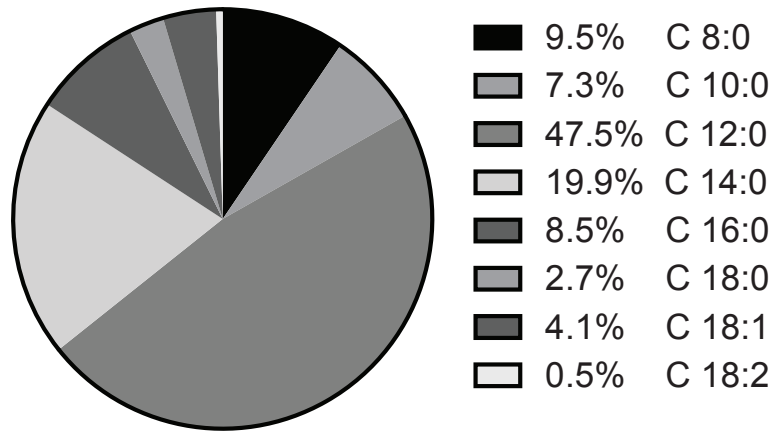

Grafikon 1. Sastav masnih kiselina ulja ploda kokosa

C 8:0 - Kaprilna; C 10:0 - Kaprinska; C 12:0 - Laurinska; C 14:0 - Miristinska; C 16:0 - Palmitinska; C 18:0 - Stearinska; C 18:1 - Oleinska; C 18:2 - Linolna

\section{Ulja sa visokim sadržajem mononezasićenih masnih kiselina (MMK)}

Mononezasićene masne kiseline imaju jednu dvostruku vezu u osnovnom ugljovodoničnom lancu, te se razlikuju MMK cis i trans konfiguracije. Konfiguracija zavisi od položaja koji vodonikovi atomi zauzimaju u prostoru oko dvostruke veze.

\section{Ulja sa visokim sadržajem oleinske kiseline}

Maslinovo ulje se među ispitivanim uzorcima izdvojilo po najvećem sadržaju oleinske kiseline $(78,5 \%)$, zatim slede bademovo ulje, ulje koštice kajsije, uljane repice, kikirikija i susama. Sadržaj oleinske kiseline u maslinovom ulju može da varira od $65 \%$ do $80 \%$ [9]. Bademovo ulje sadržalo je za $20 \%$ manje oleinske kiseline u poređenju sa maslinovim i ovi rezultati u skaldu su literaturnim podacima koji sugerišu $48 \%$ do $67 \%$ [10]. Sli- 
čan sadržaj oleinske kiseline $(61,7 \%)$ izmeren je u ulju koštice kajsije, dok se ulje kikirikija istaklo po sadržaju oleinske kiseline od $44,4 \%$, nešto nižim u poređenju sa rezultatima dobijenim od strane Zambiazi i saradnika [11]. Ulje susama je takođe pripalo grupi ulja kod kojih je najzastupljenija oleinska kiselina. Odnos nezasićenih i zasićenih masnih kiselina u susamovom ulju iznosi 5. Prema podacima iz drugih istraživanja i eruka kiselina može biti prisutna u nekim vrstama susama (oko 15,6\%), kao i a-linolenska kiselina (oko 12,5\%) [12].

Ulja koja su bogata oleinskom kiselinom su značajna u ishrani jer je pokazano da dovode do snižavanja lipida u krvi, naročito holesterola [13]. Dokazano je da oleinska kiselina utiče na inflamatorni odgovor koji karakteriše rane stadijume ateroskleroze i na taj način dovodi do smanjenja incidence kardiovaskularnih oboljenja. Oleinska kiselina se na račun zasićenih masnih kiselina ugrađuje u fosfolipidni dvosloj ćelijske membrane i smanjuje ekspresiju adhezionih molekula, naročito - vaskularnog ćelijskog adhezionog molekula (VCAM-1). Takođe smanjuje aktivaciju mRNK za ovaj molekul i interferira u aktivaciji najvažnijeg transkripcionog faktora, nuklearnog faktora kappa-B [14].

\section{Ulje sa visokim sadržajem eruka kiseline}

Ulje slačice se izdvojilo od ostalih analiziranih uzoraka po sadržaju eruka kiseline (Grafikon 2). Eruka kiselina je mononezasićena 13-dokozenska masna kiselina sa 22 C atoma. Prisutna je u količini od $41,6 \%$, dok su ostale masne kiseline zastupljene u manjem procentu. $\mathrm{U}$ drugim studijama nađene su nešto više vrednosti (47\%) [9]. Eruka kiselina dovodi do inhibicije mitohondrijalne oksidacije u srcu i u jetri, ali je inhibicija u jetri manje izražena. Inhibicija oksidacije u mitohondrijama dalje dovodi do miokardijalne lipidoze i upale srčanog mišića čime se objašnjava kardiotoksičnost eruka kiseline [15]. Uzimajući u obzir ovu osobinu eruka kiseline, integrisanje ulja slačice u svakodnevnu ishranu zahteva posebnu pažnju i opreznost.

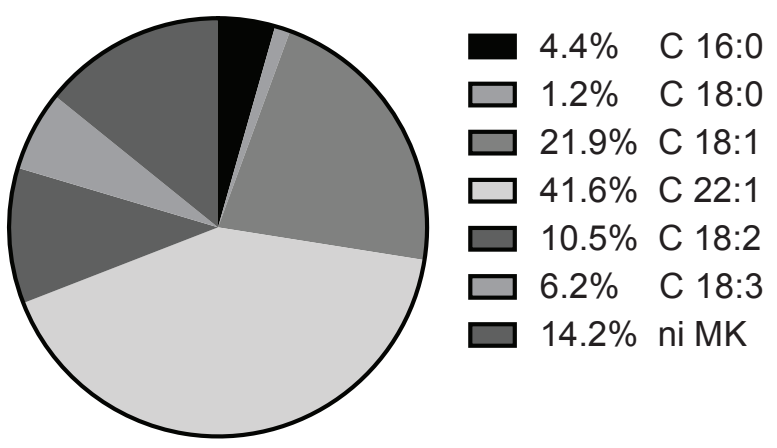

Grafikon 2. Sastav masnih kiselina ulja semena slačice C 16:0 - Palmitinska; C 18:0 - Stearinska; C 18:1 - Oleinska; C 22:1 - Eruka; 18:2 - Linolna; C 18:3 - a- Linolenska; ni MK neidentifikovane masne kiseline

\section{Ulja sa visokim sadržajem polinezasićenih masnih kiselina (PMK)}

Polinezasićene masne kiseline sadrže dve ili više dvostrukih veza u osnovnom ugljovodoničnom lancu. Polinezasićene masne kiseline, linolna i a-linolenska, spadaju u esencijalne masne kiseline. Linolna kiselina je $\omega-6$ masna kiselina, dok a-linolenska pripada grupi masnih kiselina $\omega-3$ serije.

\section{Ulja sa visokim sadržajem linolne kiseline}

U pogledu sadržaja linolne kiseline ( $>55 \%)$ grupisani su sledeći uzorci: ulje noćurka, ulje grožđa, ulje maka, suncokretovo ulje, ulje konoplje (redom). Ulje noćurka, osim što je pokazalo najviši sadržaj linolne kiseline $(75,1 \%)$, izdvojilo se u odnosu na druga ulja u pogledu sadržaja $\gamma$-linolenske kiseline (8,6\%). Dobijeni rezultati dobro se slažu sa nalazima novijeg istraživanja sprovedenog od strane Timoszuk i saradnika [16]. Zahvaljujući ovakvom sastavu masnih kiselina, ulje noćurka ostvaruje brojne pozitivne efekte na zdravlje od kojih posebno treba istaći protivupalno delovanje na koži. Za ulje semena grožđa određen je sadržaj od $66,2 \%$ linolne kiseline, što je u skladu sa opsegom vrednosti od $66 \%$ do $75,3 \%$ [17]. Suncokretovo ulje sa 59,7\% takođe pripalo je uljima bogatim linolnom kiselinom. Zastupljenost linlone kiseline može biti znatno viša, pa se u nekim uljima može naći oko 75\% [11], ali može da bude niža, do 44\% [9]. Ulje konoplje pored linolne kiseline sadrži i a-linolensku kiselinu (16,2\%), što ukupno predstavlja $71,3 \%$ esencijalnih masnih kiselina. Rezultat dobijen za ulje semena bundeve ukazuje na 44,6\% linolne kiseline, 35,3\% oleinske kiseline i 0,5\% a-linolenske kiseline. U zavisnosti od vrste biljke kao i njenog geografskog porekla, sadržaj zasićenih masnih kiselina bundevinog ulja je jako varijabilan. Naime, dok je u ovoj studiji zabeleženo samo prisustvo palmitinske i stearinske kiseline, u drugim studijama su nađene laurinska i miristinska kiselina u malom procentu (oko 4\%) [18].

\section{Ulja sa visokim sadržajem a-linolenske kiseline}

Ulje semena lana pokazalo je najveći sadržaj a-linolenske kiseline, slede ga ulje konoplje, ulje slačice i ulje uljane repice. a-linolenska kiselina čini 51,2\% ukupnog sadržaja masnih kiselina u ulju semena lana. Sadržaj a-linolenske kiseline prema drugim studijama je varirao između 35\% i 60\% [9, 19]. U ulju konoplje određen je sadržaj od 16,2\% a-linolenske kiseline. Literaturni podaci za ulje konoplju sugerišu sadržaj a-linolenske kiseline od $15 \%$ do $28 \%$ [20].

\section{Ulja sa najvišim sadržajem esencijalnih masnih kiselina}

Kada se zbirno predstavi sadržaj esencijalnih masnih kiselina (linolne i a-liolenske kiseline), ulje noćurka je pokazalo najveću vrednost. Ulje noćurka sadrži samo linolnu kiselinu, dok ulje konoplje i ulje maka sadrže 
i a-linolensku kiselinu, ali u znatno manjem procentu. Za ulje konoplje je karakterističan sadržaj linolne i a-linolenske kiseline u odnosu 3:1, što predstavlja optimalan udeo $\omega-6$ i $\omega-3$ masnih kiselina $u$ ishrani [21].

\section{ZAKLJUČAK}

U pogledu sadržaja zasićenih masnih kiselina, posebno visoke vrednosti određene su u ulju ploda kokosa i ulju ploda palme, te se zbog toga kod ovih ulja očekuje i najveća termička stabilnost. Ulja maka, konoplje i noćurka pokazala su najviši sadržaj esencijalnih masnih kiselina. Visok sadržaj a-linolenske kiseline, masne kiseline $\omega$-3 serije, zastupljen je u ulju semena lana. Ulje semena slačice je jedini uzorak u kome je utvrđeno prisustvo eruka kiseline.

Na osnovu svega navedenog može se zaključiti da su masnokiselinski profil i sastav jestivih ulja vrlo važni faktori u određivanju njihove stabilnosti kao i primene u svakodnevnoj ishrani.

\section{LITERATURA:}

1. Hooper L, Abdelhamid A, Bunn D, Brown T, Summerbell $C D$, Skeaff CM. Effects of total fat intake on body weight. Cochrane Database Syst Rev 2015; (8):CD011834.

2. Vucic V, Tepsic J, Arsic A, Popovic T, Debeljak-Martacic J, Glibetic M. Fatty acid content of vegetable oils and assessment of their consumption in Serbia. Acta Aliment 2012; 41(3):343-50.

3. Pravilnik o kvalitetu i drugim zahtevima za jestiva biljna ulja i masti, margarin i druge masne namaze, majonez i srodne proizvode. Službeni glasnik RS, 43/2013.

4. Sabolová $M$, Johanidesová A, Hasalíková E, Fišnar J, Doležal $M$, Réblová Z. Relationship between the composition of fats and oils and their oxidative stability at different temperatures, determined using the Oxipres apparatus. Eur J Lipid Sci Technol 2017; 119(9): 1600454.

5. Glick NR, Fischer MH. The role of essential fatty acids in human health. Evid-Based Complementary Altern Med 2013; 18(4):268-89.

6. Ichihara K, Fukubayashi Y. Preparation of fatty acid methyl esters for gas-liquid chromatography. J Lipid Res 2010; 51(3): 635-40.

7. Gunstone FD, 2005. Vegetable oils. In: Bailey's Industrial Oil and Fat Products. John Wiley \& Sons, Inc Gunstone FD, sixth edition 2005: 213-67.

8. Boateng L, Ansong R, Owusu W, Steiner-Asiedu M. Coconut oil and palm oil's role in nutrition, health and national development: A review. Ghana med jour 2016; 50(3):18996.

9. CHEMPRO/Top-notch technology in production of oils and fats [Internet]. Astron Tech Park, Gujarat. India; c2019 [cited 2019 Nov 01]. Available from: http://www.chempro.in/fattyacid.htm

10. Kodad O, Socias i Company R. Variability of oil content and of major fatty acid composition in almond (Prunus amygdalus Batsch) and its relationship with kernel quality. [J Agric Food Chem 2008; 56(11):4096-101.

11. Zambiazi RC, Przybylski R, Zambiazi MW, Mendonça CB. Fatty acid composition of vegetable oils and fats. Boletim do Centro de Pesquisa de Processamento de Alimentos. 2007; 25(1).

12. Asghar A, Majeed MN. Chemical characterization and fatty acid profile of different sesame verities in Pakistan. Am J Sci Indus Res. 2013; 4:540-5.

13. Lopez-Huertas E. Health effects of oleic acid and long chain omega-3 fatty acids (EPA and DHA) enriched milks. A review of intervention studies. Pharmacol Res 2010; 61(3):200-7.

14. Massaro M, Carluccio MA, De RC. Direct vascular antiatherogenic effects of oleic acid: a clue to the cardioprotective effects of the Mediterranean diet. Cardiologia (Rome, Italy). 1999; 44(6):507-13.

15. EFSA/Erucic acid a possible health risk for highly exposed children [Internet]. Euroepan Food Safety Authority; c2016 [cited 2019 Oct 21]. Available from: https://www. efsa.europa.eu/en/press/news/161109

16. Timoszuk M, Bielawska K, Skrzydlewska E. Evening primrose (Oenothera biennis) biological activity dependent on chemical composition. Antioxidants 2018; 7(8):10819.

17. Lutterodt H, Slavin M, Whent M, Turner E, Yu LL. Fatty acid composition, oxidative stability, antioxidant and antiproliferative properties of selected cold-pressed grape seed oils and flours. Food Chem 2011; 128(2):391-9.

18. Stevenson DG, Eller FJ, Wang L, Jane JL, Wang T, Inglett GE. Oil and tocopherol content and composition of pumpkin seed oil in 12 cultivars. J Agric Food Chem 2007; 55(10):4005-13.

19. Popa VM, Gruia A, Raba DN, Dumbrava D, Moldovan C, Bordean D, Mateescu C. Fatty acids composition and oil characteristics of linseed (Linum Usitatissimum L.) from Romania. J Agroaliment Processes Technol 2012; 18(2):136-40.

20. Vujasinović V, Dimić E, Arnaut M. Seme i ulje konopljehrana i lek. Journal of Edible Oil Industry 2012:43-56.

21. Leizer C, Ribnicky D, Poulev A, Dushenkov S, Raskin I. The composition of hemp seed oil and its potential as an important source of nutrition. Journal of Nutraceuticals, functional \& medical foods 2000; 2(4):35-53. 


\section{Analiza sastava masnih kiselina u jestivim biljnim uljima metodom gasne hromatografije}

Ivana Đuričić, Milica Jović, Vanja Todorović, Slađana Šobajić

Farmaceutski fakultet Univerziteta u Beogradu, Katedra za bromatologiju, Vojvode Stepe 450, 11221 Beograd, Srbija

\begin{abstract}
Kratak sadržaj
Biljna ulja su jedna od značajnih komponenti ishrane savremenog čoveka. Osim što ishrani doprinose visokom energetskom vrednošću, ulja predstavljaju veoma dobar izvor esencijalnih masnih kiselina, liposolubilnih vitamina (A, D, E i K) i provitamina (karoteni). Cilj ovog rada je bio odrediti sastav masnih kiselina u različitim biljnim uljima, razmotriti njihove povoljne i nepovoljne zdravstvene efekte, kao i termičku stabilnost shodno hemijskom sastavu. Devetnaest uzoraka različitih biljnih ulja esterifikovani su rastvorom $\mathrm{HCl}$ u metanolu. Metil estri masnih kiselina su zatim ispitivani metodom gasne hromatografije na aparatu Agilent Technologies $7890 \mathrm{~A}$ sa plameno jonizacionim detektorom. Rezultati su prikazani kao procenti pojedinačnih masnih kiselina u odnosu na ukupne. Ulja ploda kokosa i palme su se izdvojila po sadržaju zasićenih masnih kiselina (95,4\% i 49,2\%, redom). Prema sadržaju linolne kiseline grupisani su se sledeći uzorci: ulje noćurka, ulje grožđa, ulje maka, suncokretovo ulje, i ulje konoplje. Zabeležena je i specifičnost ulja semena slačice u pogledu prisustva eruka kiseline. Najveći udeo a-linolenske kiseline $(51,2 \%)$ imalo je ulje semena lana, zatim ulje semena konoplje. Usled visokog udela zasićenih masnih kiselina, kokosovo i palmino ulje mogu se smatrati najstabilnijim od svih ispitivanih uzoraka. Ulja bogata esencijalnim masnim kiselinama, linolnom i a-linolenskom kiselinom, najbolje je koristiti kao jestiva nerafinisana biljna ulja zbog očuvanja aktivnih sastojaka sa povoljnim zdravstvenim efektima.
\end{abstract}

Ključne reči: biljna ulja, zasićene masne kiseline, nezasićene masne kiseline, esencijalne masne kiseline, gasna hromatografija. 